\title{
CONSCIÊNCIA SAUDÁVEL E CONFIANÇA DO CONSUMIDOR: UM ESTUDO SOBRE A APLICAÇÃO DA TEORIA DO COMPORTAMENTO PLANEJADO NA COMPRA DE ALIMENTOS ORGÂNICOS
}

\author{
Thaíssa Velloso Castelo Branco \\ Mestranda em Administração \\ Universidade de Brasília - UnB \\ Brasília - Distrito Federal - Brasil \\ thaissavelloso@gmail.com \\ Eluiza Alberto de Morais Watanabe \\ Doutora em Administração \\ Universidade de Brasília - UnB \\ Brasília - Distrito Federal - Brasil \\ eluizaw@gmail.com \\ Solange Alfinito \\ Doutora em Psicologia Social, do Trabalho e das Organizações \\ Universidade de Brasília - UnB \\ Brasília - Distrito Federal - Brasil \\ salfinito@unb.br
}

\section{RESUMO}

O objetivo da pesquisa foi analisar os fatores que influenciam o consumo de alimentos orgânicos, e sua relação com a intenção de compra utilizando a Teoria do Comportamento Planejado (TCP) como base. Especificamente, analisou-se a influência da inserção da confiança do consumidor e da consciência saudável na TCP. Foram aplicados 251 questionários junto a consumidores de frutas, legumes e hortaliças orgânicas. A análise de dados foi feita por meio da Modelagem por Equações Estruturais. Os resultados mostraram que as normas subjetivas, atitude e controle percebido influenciam diretamente a intenção de compra de orgânicos. Em contrapartida, a confiança não foi significativa no modelo de predição. Por fim, a consciência saudável impactou a intenção de compra, mas de forma pouco expressiva. Assim, os resultados reforçam a estabilidade da estrutura original da TCP, já que a adição da confiança e da consciência saudável não aumentaram a explicação do modelo. A pesquisa contribui, ainda, para a diminuição da lacuna de estudos brasileiros sobre o tema, aprofundando o entendimento quanto ao mercado de alimentos orgânicos e identificando a importância da norma subjetiva social e da atitude na intenção de compra dos consumidores. Implicações adicionais são discutidas e apontam que a adição da confiança e da consciência saudável não agrega poder ao modelo, direcionando futuras pesquisas.

Palavras-chave: Alimentos orgânicos. Confiança. Consciência saudável. Teoria do comportamento planejado

\section{HEALTHY CONSCIOUSNESS AND CONSUMER TRUST: A STUDY ON THEORY OF PLANNED BEHAVIOR IN THE PURCHASE OF ORGANIC FOODS}

\begin{abstract}
The purpose of this research was to analyze the factors that influence organic food consumption, and their relationship with the purchase intention, applying the Theory of Planned Behavior (TPB). Specifically, we analyzed the influence of adding two new variables to the TPB: consumer trust and healthy consciousness. Thus, we applied 251 questionnaires with consumers of organic fruits and vegetables, and used Structural Equation Modeling for data analysis. The results showed that subjective norms, attitude and perceived control directly influence purchase intention. On the other hand, trust was not significant in the prediction model. Finally, healthy consciousness directly influenced the purchase intention, but in a poor way. Thus, the results reinforce the stability of the original structure of the TPB, as the addition of trust and healthy consciousness did not increase the model explanation. Nevertheless, this research contributes to the reduction of the lack of Brazilian studies about the topic, deepening the understanding of the organic food market, and identifying the importance of social subjective norms and on the consumer purchase intention attitude. Further implications are discussed.
\end{abstract}

Key words: Healthy consciousness. Organic foods. Theory of planned behavior. Trust. 


\section{INTRODUÇÃO}

O Brasil tem o maior mercado consumidor de produtos orgânicos na América Latina e o terceiro em termos de área produtiva de orgânicos. Alguns países, tais como Argentina, Peru, Chile e Colômbia, possuem uma produção amplamente orientada para a exportação desses produtos, enquanto o Brasil conta com uma produção crescente para suprir a também crescente demanda interna (Willer \& Lernoud, 2018). Tal fato salienta a importância de se aprofundar o entendimento em relação ao consumidor de orgânicos no Brasil.

Muitos aspectos contribuem para o consumo e compra de alimentos orgânicos. Estudos abordando questões relacionadas à saúde, perfil socioeconômico, sabor do produto, preço de venda e preocupação com o meio ambiente são os que se destacam no cenário brasileiro (Albuquerque Júnior, Silva Filho, Costa, \& Santos, 2013; Braga Junior, Veiga Neto, \& Moraes, 2014; Lima-Filho \& Quevedo-Silva, 2012), sendo a primeira em maior destaque.

Já em levantamento de estudos estrangeiros, a Teoria do Comportamento Planejado (TCP) se sobressai na investigação de preditores do consumo de orgânicos (Scalco, Noventa, Sartori, \& Ceschi, 2017). A TCP defende que atitude, normas subjetivas e controle comportamental percebido predizem a intenção de compra que, por sua vez, prediz o comportamento (Ajzen, 1991). A teoria permite que outras dimensões sejam acrescentadas à TCP. Talvez, por esta flexibilidade, ela seja tão popular no mundo. No Brasil, no entanto, a teoria é ainda pouco explorada em estudos sobre alimentos orgânicos (Albuquerque Júnior et al., 2013; Hoppe, Vieira, \& de Barcellos, 2013).

Uma outra dimensão motivadora do consumo de alimentos orgânicos é a confiança do consumidor (Janssen \& Hamm, 2014; Nuttavuthisit \& Thøgersen, 2017). Ela é considerada um fator decisivo para a compra desse tipo de alimento, e emprega a certificação para garantir a veracidade das informações passadas pelos agentes envolvidos (Teng \& Wang, 2015).

Neste contexto, esta pesquisa tem como objetivo analisar fatores que influenciam a intenção de compra de consumidores de alimentos orgânicos utilizando a Teoria do Comportamento Planejado. Especificamente, pretende-se analisar e testar a inserção da confiança do consumidor e da consciência saudável na TCP. A inclusão da confiança deve-se à sua alta relevância na tomada de decisão de compra de alimentos orgânicos e o pouco aprofundamento de sua influência sobre a compra (Nuttavuthisit \& Thøgersen, 2017; Teng \& Wang, 2015; Won Suh, Eves, \& Lumbers, 2015). A inclusão da dimensão de consciência saudável se justifica tendo em vista que aspectos relacionados à saúde são os preditores mais estudados nacionalmente (Albuquerque Júnior et al., 2013; Andrade \& Bertoldi, 2012; Lima-Filho \& Quevedo-Silva, 2012; Rodrigues, Carlos, Mendonça, \& Correa, 2009).

Pesquisa da AC Nielsen, realizada no ano de 2017, mostrou que consumidores latinoamericanos se mostram cada vez mais preocupados com problemas de saúde e procuram alimentos locais, frescos e orgânicos. Alguns outros dados podem ser destacados como o fato de $67 \%$ dos brasileiros afirmarem que preferem comprar em varejistas especializados a fim de encontrar maior oferta de alimentos saudáveis, assim como $76 \%$ dos brasileiros afirmam que leem os rótulos para analisar o conteúdo nutricional dos alimentos. Essas particularidades e características do consumidor brasileiro evidenciam a importância de uma investigação mais aprofundada acerca do seu comportamento e motivadores que o levam a compra. Portanto, uma vez que a Teoria do Comportamento Planejado foi desenvolvida com o objetivo de prever o comportamento humano em um contexto específico (Ajzen, 1991), sua aplicação em âmbito nacional pode contribuir para o melhor entendimento a respeito do consumidor brasileiro, ainda pouco investigado quando o assunto é alimentação orgânica.

\section{REFERENCIAL TEÓRICO}

\subsection{Teoria do Comportamento Planejado (TCP): origem e evolução}


A Teoria do Comportamento Planejado (TCP) foi criada para desvendar e prever o comportamento humano em um contexto específico. Nela, os fatores atitude, controle comportamental percebido e normas subjetivas conduzem à formação de uma intenção comportamental (Ajzen, 1991). A TCP evoluiu da Teoria da Ação Racional (TAR) (Ajzen \& Fishbein, 1980) que, por isso, é também abordada a seguir.

A TAR foi desenvolvida para predizer comportamentos que podem ser facilmente realizados se a pessoa desejar (Ajzen, 1985). Ela propõe que a intenção comportamental do indivíduo depende de duas dimensões: atitude e norma subjetiva (Ajzen, 1985). A atitude diz respeito à avaliação favorável ou desfavorável com relação ao comportamento de interesse, e as normas subjetivas referem-se à percepção de uma pressão social para executar ou não um comportamento (Ajzen, 1991). Ajzen (2002) reitera que a norma subjetiva é estipulada pelo conjunto total de opiniões normativas acessíveis no tocante às expectativas das referências importantes para o indivíduo como, por exemplo, família e amigos.

Com o objetivo de contemplar tanto as influências pessoais quanto sociais sobre o comportamento, a TAR propõe que medidas de atitude e de norma subjetiva sejam tomadas juntas. Uma atitude favorável tem probabilidade de não se transformar em ação devido à pressão social para não realizar o comportamento (Webb \& Sheeran, 2006). Ou seja, o indivíduo tem a intenção de realizar um comportamento quando o avalia positivamente e quando crê que as outras pessoas importantes pensam que ele deveria realizá-lo (Ajzen, 1985).

Devido às limitações da TAR para tratar de comportamentos que os indivíduos não têm o controle completo da vontade, surgiu a Teoria do Comportamento Planejado (TCP), na qual o controle comportamental percebido é a dimensão adicionada e desempenha um papel importante. Diz respeito à facilidade ou dificuldade percebida pelas pessoas em desempenhar o comportamento de interesse (Ajzen, 1991). Ou seja, pela TCP a intenção comportamental depende de três dimensões: atitude, norma subjetiva e controle comportamental percebido.

A intenção e o controle comportamental percebido são adotados diretamente para prever a realização do comportamento. Em função disso, a intenção comportamental consiste na preparação do indivíduo para realizar um comportamento e ocupa o papel de antecedente imediato do comportamento real (Ajzen, 1991). Como regra geral, a intenção de realizar um comportamento adquire força, quanto maior for o controle comportamental percebido e quanto mais favorável for a atitude e as normas subjetivas. A relevância de cada dimensão na predição da intenção varia entre comportamento e situação (Ajzen, 1991).

Segundo $\mathrm{Wu}$, Yeh e Hsiao (2011), a intenção de compra consiste na possibilidade de os consumidores planejarem ou estarem dispostos a comprar futuramente um determinado produto ou serviço. Na literatura, ela tem sido amplamente empregada como um preditor de compra posterior (Kuo, Wu, \& Deng, 2009). Inclusive, o resultado do estudo de Armstrong, Morwitz e Kumar (2000) converge para o mesmo pensamento e sugere que as intenções têm grande valor para as previsões de venda.

\subsection{TCP no mercado de alimentos orgânicos e variações da TCP}

Nesse contexto de consumo de alimentos orgânicos, diversos estudos apontam a importância da TCP na compreensão do comportamento dos consumidores. Gallo, Marín e Flores (2014) usaram a TCP para investigar os consumidores de alimentos orgânicos em Madri, Espanha. Eles verificaram que o modelo pode ser aplicado para prever a intenção de compra de alimentos orgânicos e, através dele, é possível detectar diferenças de intenção entre marca do fabricante e marca do distribuidor. A atitude foi um fator relevante para as marcas analisadas e o controle comportamental percebido essencial na determinação do comportamento de compra.

Adicionalmente, Ajzen (1991) afirma que a TCP está aberta para a inserção de preditores adicionais desde que seja demonstrado um aumento significativo da influência sobre a intenção e o comportamento após a consideração de novas variáveis. Com isso, diferentes estudos optaram por 
incluir novas dimensões à teoria na esperança de aumentar o seu poder preditivo. Nesta linha, são apresentados alguns exemplos.

Albuquerque Júnior et al. (2013) utilizaram a TCP como base e relacionaram a saúde e o meio ambiente com os construtos originais em um estudo realizado em Fortaleza, Ceará. Os resultados revelaram que os fatores ligados à saúde, juntamente com as dimensões relativas à normas subjetivas, controle comportamento percebido e atitude, são aspectos importantes relacionados ao consumo de alimentos orgânicos. Já o estudo de Liang (2014) relacionou os pressupostos da TCP com o estilo de vida. Ele verificou o comportamento de compra online de orgânicos com consumidores que possuem diferentes estilos de vida relacionados à alimentação. Como resultado, apontou o fator atitude como aquele que mais influencia a intenção de compra, seguido pelo controle comportamental percebido e normas subjetivas. Essas variáveis independentes apresentaram efeitos distintos sobre a intenção de compra dos diferentes estilos de vida.

Teng e Wang (2015), por sua vez, usaram alguns fatores, tais como confiança, atitudes e normas subjetivas, para investigar como as informações do rótulo e o conhecimento sobre orgânicos influenciam a intenção de compra desses alimentos. Para montar seu modelo, utilizaram duas dimensões da TCP e uma dimensão (confiança) do Modelo de Decisão do Consumidor. Os resultados mostraram que a confiança, como antecedente de atitude, se mostra um mediador significativo das relações entre informação revelada, conhecimento e intenção de compra orgânica. O conhecimento sobre orgânicos não influenciou consideravelmente as atitudes dos consumidores. Já as atitudes e normas subjetivas tiveram um impacto significativo sobre a intenção de compra orgânica.

Yazdanpanah e Forouzani (2015) utilizaram a teoria a fim de investigar a intenção de compra de orgânicos no Irã. Aumentaram significativamente o poder explicativo do modelo padrão ao adicionar os preditores de norma moral e autoidentidade. Esse estudo também revelou em seus resultados que a atitude dos iranianos foi o principal preditor da intenção de compra de orgânicos. $\mathrm{O}$ controle comportamental percebido e as normas subjetivas não se mostraram significativos nesta pesquisa.

O estudo de Won Suh et al. (2015) indicou que a experiência passada do consumidor é o fator que mais influencia a intenção de compra orgânica, seguido por atitude, norma subjetiva, confiança e controle comportamental percebido. O preço foi identificado como determinante do comportamento de compra real.

Em mais um exemplo, Vassallo, Scalvedi e Saba (2016), para investigar o contexto de alimentos sustentáveis na Itália, utilizaram a TCP estendida com a inclusão da dimensão do comportamento passado que, por sua vez, se mostrou um motivador significativo na compra desses alimentos. A intenção de compra foi mais influenciada pela atitude do que pelos quatro componentes da norma subjetiva (família, pessoas importantes, amigos e sociedade). Destaca-se que a norma subjetiva relacionada à família, em comparação às outras três, teve maior força. Por fim, o controle comportamental percebido também foi preditor da intenção de compra dos consumidores.

Na pesquisa de Yadav e Pathak (2016), a TCP apoiou parcialmente a intenção de compra de alimentos orgânicos na Índia, pois as normas subjetivas não influenciaram significativamente a intenção de compra enquanto os outros dois constructos (atitude e controle comportamental percebido) apresentaram um impacto relevante. Isso quer dizer que a compra de alimentos orgânicos ainda não se tornou uma norma social em uma nação em desenvolvimento como a Índia (Yadav \& Pathak, 2016). A adição de novas dimensões (atitude moral, preocupação ambiental e consciência saudável) melhorou a capacidade preditiva do modelo com destaque para a atitude moral e consciência saudável que influenciaram positivamente a intenção.

Dean, Raats e Shepherd (2012) identificaram que as normas subjetivas e a atitude influenciam a intenção para consumir tomates orgânicos frescos e processados. Já o controle comportamental percebido foi preditor da intenção de compra somente dos orgânicos frescos. Todas 
as dimensões adicionais (normas morais, comportamento passado e autoidentidade) colaboraram para a predição da intenção de compra de ambos os tipos de orgânicos, superando o impacto das dimensões originais da TCP.

O estudo de Hoppe et al. (2013) replicou o modelo da TCP no Brasil, em Porto Alegre, Rio Grande do Sul. Ao pesquisar consumidores de tomates orgânicos em dois canais de distribuição, os resultados revelaram que atitude e controle percebidos influenciaram consideravelmente a intenção de consumo. Já as normas subjetivas e a variável adicional, incerteza percebida, não apresentaram efeito expressivo sobre a intenção de compra.

Os estudos descritos mostram a importância das dimensões originais e adicionais da TCP para prever a intenção de compra dos consumidores com o intuito de aumentar o poder de explicação do modelo. Destaca-se que a maioria dos estudos revela o impacto positivo das normas subjetivas, do controle comportamental percebido e da atitude na intenção de compra dos consumidores de alimentos orgânicos. Assim, com base na TCP de Ajzen (1991), a primeira hipótese de pesquisa (H1) é apresentada: o controle comportamental percebido (H1a), as normas subjetivas (H1b), e a atitude (H1c) influenciam positivamente a intenção de compra dos consumidores de alimentos orgânicos.

\subsection{A confiança no contexto de alimentos orgânicos}

Em lugares onde o mercado de orgânicos é pequeno e não desenvolvido, as pessoas em geral têm consciência e conhecimento limitado a respeito desse tipo de alimento (Teng \& Wang, 2015). Segundo Rousseau, Sitkin, Burt e Camerer (1998), a confiança é um estado psicológico que engloba $\mathrm{o}$ intuito de aceitar a vulnerabilidade fundamentado nas expectativas positivas das intenções e comportamentos do outro.

É preciso destacar também que os atributos dos alimentos orgânicos são atributos de credibilidade, ou seja, não são perceptíveis pelo consumidor mesmo depois da compra ou consumo. Em outras palavras, o cliente não sabe se o produto é orgânico a menos que ele seja informado (Giannakas, 2002). Diante disso, é necessário considerar a confiança dos consumidores como prérequisito para o desenvolvimento desse tipo de mercado (Nuttavuthisit \& Thøgersen, 2017).

Torjusen, Sangstad, Jensen e Kjærnes (2004) trazem uma perspectiva ainda mais aprofundada de confiança fazendo a distinção entre confiança pessoal e no sistema. A confiança pessoal ocorre na interação entre duas pessoas conhecidas entre si. A urbanização diminui a possibilidade das relações se fundamentarem na confiança pessoal, pois aumenta a distância física entre produtores e consumidores. Por sua vez, a confiança do sistema é enraizada em instituições e uma estratégia para desenvolvê-la seria a rotulação de produtos verdes, por exemplo. A distinção entre os dois tipos de confiança foi considerada nessa pesquisa.

Segundo Lombardi, Moori e Sato (2004), a credibilidade das instituições certificadoras é determinante da confiança que distribuidores e consumidores atribuem ao produto oferecido e, por isso, desempenha papel de destaque nessa cadeia produtiva. Para Zakowska-Biemans (2011), a baixa confiança no sistema de controle e rotulagem orgânica pode ser resultado da falta de conhecimento sobre certificação de alimentos orgânicos.

Estudos comprovam que a confiança desempenha um papel fundamental na escolha de alimentos orgânicos. Teng e Wang (2015) demonstraram a importância deste construto como preditor da intenção de compra assim como o estudo de Won Suh et al. (2015). Em contrapartida, Andrade e Bertoldi (2012) realizaram uma pesquisa em Belo Horizonte e constaram que a minoria dos consumidores entrevistados se certifica que o produto realmente é orgânico pela presença do selo de certificação. Logo, para a pesquisa, a confiança não é fator determinante para a escolha.

Já Nuttavuthisit e Thogersen (2017) analisaram a importância da confiança utilizando a a TCP como estrutura básica para a pesquisa sobre a tomada de decisão dos consumidores tailandeses de orgânicos. Os resultados revelaram que a falta de confiança reduz as expectativas dos consumidores sobre os benefícios de comprar alimentos orgânicos, tornando-os menos propensos a

Revista de Gestão Social e Ambiental - RGSA, São Paulo, v. 13, n. 1, p. 02-20, jan./abr. 2019. 
adquirir esse tipo de comida. A intenção de compra orgânica depende, sobretudo, da atitude, mas também é influenciada significativamente pela norma subjetiva. O controle comportamental percebido não exerceu um papel sobre a intenção de compra dos respondentes.

Assim, entre resultados positivos e negativos identificados na literatura, a dimensão confiança se destaca já que, em decisões de compras de alimentos orgânicos, ela pode ser mais importante do que em decisões de compras de alimentos convencionais. Consequentemente, ante a importância da confiança no contexto de compra de alimentos orgânicos e a verificação da pertinência da TCP aplicada a este mercado, emerge a segunda hipótese (H2) de que a inclusão da confiança ao modelo original da TCP de Ajzen (1991) é relevante, podendo aumentar seu poder preditivo na avaliação da intenção de compra para esse mercado.

\subsection{Saúde e consciência saudável}

Os aspectos relacionados à saúde também são importantes na compreensão do comportamento dos consumidores de alimentos orgânicos. O estudo de Albuquerque Júnior et al. (2013) revelou que os fatores ligados à saúde são os que mais influenciam a compra de orgânicos pelos consumidores de Fortaleza-CE. Lima-Filho e Quevedo-Silva (2012), em um estudo sobre a percepção dos consumidores sobre produtos orgânicos em Campo Grande-MS, reconheceram que, em comparação aos produtos convencionais, os entrevistados consideram que os orgânicos fazem melhor à saúde.

O estudo de Rodrigues et al. (2009) buscou apontar os fatores que influenciam o consumo de orgânicos em Ribeirão Preto, São Paulo. Os resultados apontaram que a preocupação com a saúde, a maior percepção de qualidade e sabor oferecida por esses alimentos, assim como, o número elevado de nutrientes e as crenças sobre seus benefícios fazem com que os consumidores busquem os produtos orgânicos.

Adicionalmente, Andrade e Bertoldi (2012), com o objetivo de identificar as motivações em relação ao consumo de alimentos orgânicos, constataram que a preocupação com a saúde se destaca entre os motivadores. Por sua vez, Yadav e Pathak (2016) investigaram os preditores da intenção de compra de consumidores de alimentos orgânicos na Índia e os resultados mostraram que esta dimensão atua como forte preditora da intenção de compra. Por isso, os autores recomendam que ela seja inserida no modelo do TCP.

Assim, desponta a terceira hipótese (H3), onde a dimensão da Consciência Saudável, relativa à importância e às boas práticas relacionadas à saúde, mostra-se importante para avaliar o contexto do mercado de alimentos orgânicos, bem como é capaz de aumentar o poder preditivo do modelo original da TCP de Ajzen (1991) em relação à intenção de compra.

\subsection{Modelo conceitual da pesquisa}

Considerando que construções adicionais à TCP são permitidas e vêm apresentando êxito, essa pesquisa propõe acrescentar as dimensões confiança e consciência saudável ao modelo original reduzido, como mostra a Figura 1. Assim, inclui não apenas os principais preditores estudados internacionalmente e que compõem as dimensões da TCP, mas também duas dimensões que têm demonstrado resultados promissores em estudos em outros países, a consciência saudável e a confiança do consumidor (Nuttavuthisit \& Thøgersen, 2017; Teng \& Wang, 2015; Won Suh et al., 2015; Yadav \& Pathak, 2016). 


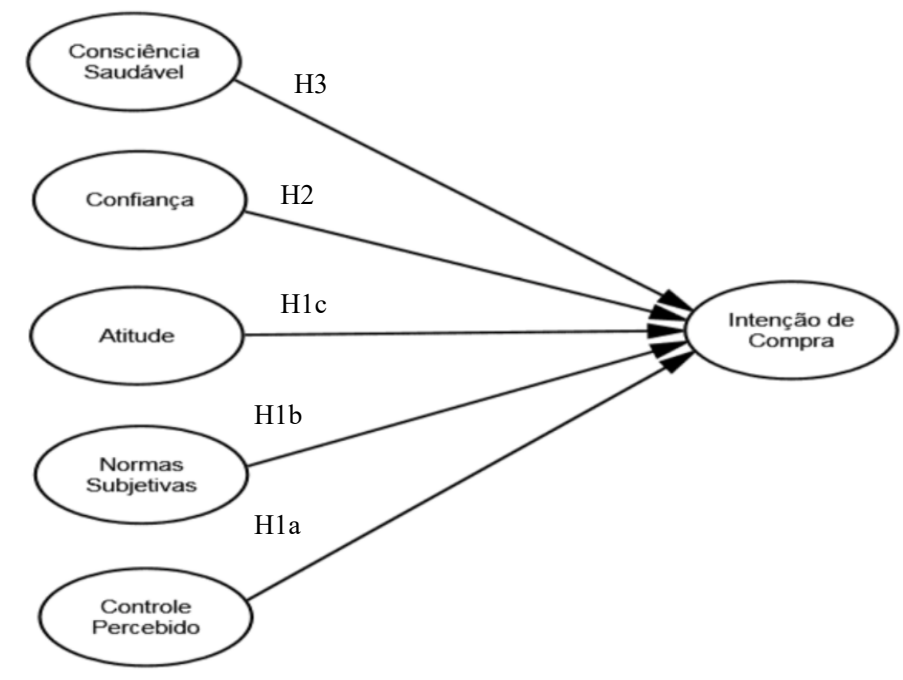

Figura 1. Modelo teórico de pesquisa

Fonte: Adaptado de Ajzen (1991), Nuttavuthisit e Thøgersen (2017) e Tarkiainen e Sundqvist (2005)

De acordo com o modelo teórico proposto na Figura 1, busca-se identificar a influência das variáveis independentes, controle comportamental percebido (H1a), normas subjetivas (H1b), atitude (H1c), confiança do consumidor (H2) e consciência saudável (H3), sobre a intenção de compra de alimentos orgânicos. Para tanto, os alimentos orgânicos delimitados para a investigação foram as frutas, legumes e hortaliças (FLH) in natura por compreenderem os itens de alimentos orgânicos mais disponíveis no mercado e, mais frequentemente, presentes na cesta de consumidores de orgânicos no Brasil (Conselho Brasileiro da Produção Orgânica e Sustentável - Organis / Market Analysis, 2017).

\section{MÉTODO}

O estudo foi conduzido no Brasil e os respondentes compreenderam somente compradores de FLH orgânicas. A amostra total foi de 251 consumidores e, após o tratamento dos dados, 40 questionários foram excluídos, sendo 14 por apresentarem casos omissos e 26 casos extremos. Assim, restaram 211 questionários válidos que, de acordo com Cohen (1992), consistiu em um poder estatístico post hoc (1- $\beta$ ) de 0,996 , para um efeito médio de 0,15 e significância de 0,05 . E para verificar a normalidade multivariada dos dados, o Teste de Mardia foi realizado e apresentou valor de 106,6 e razão crítica (critical ratio) de 21,08. Com isso, o bootstrap (teste nãoparamétrico) foi empregado (Marôco, 2010).

A maioria dos respondentes era de mulheres $(73,5 \%)$, e as faixas de idade predominantes foram as de 20 a 25 anos com $28,9 \%$ e de 30 a 40 anos com $25,6 \%$. Um pouco mais da metade dos pesquisados $(50,7 \%)$ afirmaram não ter filhos. Quanto ao grau de escolaridade, $41,7 \%$ indicaram possuir pós-graduação e somente $0,9 \%$, o fundamental incompleto. Cerca de 45,0\% dos respondentes eram solteiros e 40,3\% casados. Com relação à renda familiar mensal, 29,4\% pertenciam à faixa de $\mathrm{R} \$ 9.370,00$ a $\mathrm{R} \$ 18.740,00$ e $28 \%$ com renda acima de $\mathrm{R} \$ 18.740,00$.

Adotou-se como instrumento de coleta de dados um questionário estruturado, autoadministrado, contendo uma pergunta filtro, 26 itens das escalas referentes ao estudo e seis questões sociodemográficas. Na aplicação do questionário, o mesmo foi iniciado com a pergunta filtro: "Você compra frutas, legumes ou hortaliças orgânicas?". Apenas aqueles que responderam "sim" puderam prosseguir, resguardando a composição da amostra unicamente com consumidores de alimentos orgânicos. Em seguida, os respondentes foram requisitados a indicar seu grau de concordância quanto às afirmações relativas às dimensões de Normas Subjetivas, Controle Comportamental Percebido, Consciência Saudável e Confiança em escala Likert, variando entre 1- 
discordo totalmente e 5-concordo totalmente. Nos itens relativos à Intenção de compra, os participantes deveriam indicar com que frequência pretendiam comprar frutas, legumes e hortaliças orgânicas no mês posterior. Para isso, adotou-se uma escala tipo Likert de frequência, variando de 1-nunca a 5-sempre. Por fim, os itens de atitude seguiram uma escala tipo Likert, variando entre 1muito negativa e 5-muito positiva.

Os itens da TCP, seguiram as instruções de Ajzen (1991) e adaptações sugeridas por Nuttavuthisit e Thøgersen (2017) para alimentos orgânicos, resultando em 17 itens, a saber: Atitude ( 3 itens; $\alpha=0,94$ ), normas subjetivas ( 6 itens; $\alpha=0,92$ ), controle comportamental percebido ( 5 itens; $\alpha=0,83$ ), intenção de compra (3 itens; $\alpha=0,94$ ). Os itens de confiança foram adaptados de Nuttavuthisit e Thøgersen (2017), que continha oito itens e dois fatores (Confiança no Sistema e Confiança Pessoal), dois quais dois itens foram eliminados por não possuir sentido para o contexto brasileiro. Assim, a Confiança no Sistema foi acessada por quatro itens $(\alpha=0,93)$, e a Confiança Pessoal por dois itens $(\alpha=0,75)$. Por fim, a consciência saudável ( 3 itens; $\alpha=0,81$ ) foi medida segundo a escala desenvolvida por Tarkiainen e Sundqvist (2005). O instrumento foi, então, submetido ao processo de tradução reversa (Brislin, 1970) e à validação semântica e por juízes (Pasquali, 1999). As dimensões e itens do instrumento são apresentados na figura 2.

O questionário foi desenvolvido na plataforma Google Forms e disponibilizado online por cerca de um mês, entre abril e maio de 2017. Cabe ressaltar que este instrumento assegurou o anonimato e a liberdade de recusa a responder qualquer questão. Ademais, os respondentes foram recrutados por conveniência, por amostragem não-probabilística. Para o recrutamento foi adotado o método de snowball, sendo o instrumento disponibilizado via redes sociais e e-mail. Além de compartilhar o questionário pelas redes sociais, foi feita a sua divulgação em grupos do Facebook voltados para alimentação orgânica no intuito de alcançar o público-alvo da pesquisa. Aqueles que se dispusessem a participar da pesquisa eram convidados a enviar o questionário para outras pessoas. Cabe mencionar que, de acordo com Rife, Cate, Kosisnki e Stillwell (2016), a amostragem com o uso de redes sociais como o Facebook tem se mostrado válido, com resultados fidedignos àqueles identificados em formas mais convencionais de recrutamento.

\begin{tabular}{|c|l|l|}
\hline Dimensões & & Itens \\
\hline \multirow{4}{*}{$\begin{array}{c}\text { Intenção de } \\
\text { compra }\end{array}$} & Int1 & $\begin{array}{l}\text { Por favor, indique com que frequência você pretende comprar hortaliças orgânicas no } \\
\text { próximo mês. }\end{array}$ \\
\cline { 2 - 3 } & Int2 & $\begin{array}{l}\text { Por favor, indique com que frequência você pretende comprar frutas orgânicas no } \\
\text { próximo mês. }\end{array}$ \\
\cline { 2 - 3 } & Int3 & $\begin{array}{l}\text { Por favor, indique com que frequência você pretende comprar legumes orgânicos no } \\
\text { próximo mês. }\end{array}$ \\
\hline \multirow{4}{*}{ Atitude } & At1 & $\begin{array}{l}\text { Numa escala de 1 a 5, indique, por favor, o que melhor descreve a sua opinião em } \\
\text { relação à compra de hortaliças orgânicas ao invés de convencionais. }\end{array}$ \\
\cline { 2 - 4 } & At2 & $\begin{array}{l}\text { Numa escala de 1 a 5, indique, por favor, o que melhor descreve a sua opinião em } \\
\text { relação à compra de frutas orgânicas ao invés de convencionais. }\end{array}$ \\
\cline { 2 - 4 } & At3 & $\begin{array}{l}\text { Numa escala de 1 a 5, indique, por favor, o que melhor descreve a sua opinião em } \\
\text { relação à compra de legumes orgânicos ao invés de convencionais. }\end{array}$ \\
\hline \multirow{4}{*}{$\begin{array}{c}\text { Normas } \\
\text { subjetivas }\end{array}$} & Norm1 & Existe a expectativa de que eu compre hortaliças orgânicas ao invés de convencionais. \\
\cline { 2 - 3 } & Norm2 & Pessoas parecidas comigo compram hortaliças orgânicas. \\
\cline { 2 - 3 } & Norm3 & Existe a expectativa de que eu compre frutas orgânicas ao invés de convencionais. \\
\cline { 2 - 3 } & Norm4 & Pessoas parecidas comigo compram frutas orgânicas. \\
\cline { 2 - 3 } & Norm5 & Existe a expectativa de que eu compre legumes orgânicos ao invés de convencionais. \\
\cline { 2 - 3 } & Norm6 & Pessoas parecidas comigo compram legumes orgânicos. \\
\hline \multirow{4}{*}{$\begin{array}{c}\text { Pontrole } \\
\text { Percebido }\end{array}$} & Contr1 & Alimentos orgânicos são caros. \\
\cline { 2 - 3 } & Contr2 & Alimentos orgânicos são fáceis de encontrar. \\
\cline { 2 - 3 } & Contr3 & Eu sei bastante sobre alimentos orgânicos. \\
\cline { 2 - 3 } & Contr4 & Eu sou um/a dos/as especialistas em alimentos orgânicos entre meus conhecidos. \\
\cline { 2 - 3 } & Contr5 & Sinto que sou bem informado/a sobre alimentos orgânicos. \\
\hline & & \\
\hline
\end{tabular}

Revista de Gestão Social e Ambiental - RGSA, São Paulo, v. 13, n. 1, p. 02-20, jan./abr. 2019. 


\begin{tabular}{|c|c|c|}
\hline \multirow{3}{*}{$\begin{array}{l}\text { Consciência } \\
\text { saudável }\end{array}$} & Saud1 & Eu escolho alimentos cuidadosamente para assegurar uma boa saúde. \\
\hline & Saud2 & Eu não me considero um/a consumidor/a com consciência saudável. \\
\hline & Saud3 & Eu penso frequentemente sobre questões relacionadas à saúde. \\
\hline \multirow{4}{*}{$\begin{array}{l}\text { Confiança } \\
\text { no sistema }\end{array}$} & Conf1 & $\begin{array}{l}\text { Eu acredito que o Ministério da Agricultura, Pecuária e Abastecimento é qualificado } \\
\text { para credenciar organizações certificadoras de alimentos orgânicos. }\end{array}$ \\
\hline & Conf2 & $\begin{array}{l}\text { Eu acredito na qualificação das organizações certificadoras de alimentos orgânicos } \\
\text { credenciadas pelo Ministério da Agricultura, Pecuária e Abastecimento e Inmetro. }\end{array}$ \\
\hline & Conf3 & Eu confio no controle do Governo em relação aos produtos orgânicos. \\
\hline & Conf4 & $\begin{array}{l}\text { Eu confio nos produtos orgânicos brasileiros já que eles são certificados por } \\
\text { organizações credenciadas junto ao Ministério da Agricultura, Pecuária e } \\
\text { Abastecimento e ao Inmetro. }\end{array}$ \\
\hline \multirow{2}{*}{$\begin{array}{l}\text { Confiança } \\
\text { pessoal }\end{array}$} & Conf5 & $\begin{array}{l}\text { Eu confio mais em produtos orgânicos comprados diretamente de produtores não } \\
\text { certificados. }\end{array}$ \\
\hline & Conf6 & Eu não preciso de certificação, eu acredito na palavra dos produtores. \\
\hline
\end{tabular}

Figura 2. Dimensões e itens do instrumento aplicado

Fonte: Adaptado de Nuttavuthisit e Thøgersen (2017) e Tarkiainen e Sundqvist (2005)

No que se refere à análise de dados, os softwares SPSS (versão 20) e Amos (versão 21) foram utilizados para conduzir a Modelagem por Equações Estruturais (MEE). Segundo Hair, Anderson, Tatham e Black (2005), a MEE é o melhor método para a análise de dados quando se deseja examinar a relação de dependência entre variáveis que possuem múltiplas relações de dependência e independência, como é o caso dessa pesquisa.

\section{RESULTADOS}

Primeiramente, os construtos foram submetidos à Análise Fatorial Confirmatória (AFC), para verificar a validade convergente (se os indicadores de cada construto são coerentes entre si) e a validade discriminante (se as variáveis do modelo mensuram construtos diferentes entre si). Por fim, para investigar as relações contempladas no modelo de pesquisa, foi empregada a Modelagem por Equações Estruturais (Byrne, 2016).

Para a AFC, o método utilizado foi o da Estimação por Máxima Verossimilhança (MLMaximum Likelihood) (Brown, 2014). O modelo de mensuração contou com oito construtos. Observa-se que o item Contr1 ("Os alimentos orgânicos são caros"), pertencente à dimensão do Controle Percebido, foi excluído da análise, pois não foi significativo $(p=0,07)$. $O$ modelo de mensuração resultou em 28 variáveis observadas.

Quanto à dimensão de Normas Subjetivas, ela foi dividida em duas outras variáveis latentes: Norma Subjetiva Social (3 itens) e Norma Subjetiva Interna (3 itens). A primeira dimensão se relaciona com a expectativa social percebida pelo respondente em relação à sua compra de alimentos orgânicos, e a segunda com a percepção de quanto pessoas semelhantes ao respondente compram alimentos orgânicos. A nova configuração das Normas Subjetivas se mostrou adequada estatisticamente por meio da AFC e já era esperada por Nuttavuthisit e Thøgersen (2017).

Para identificar problemas no modelo, os Índices de Modificação (IM) foram analisados e nenhum problema foi identificado. Posteriormente, os índices de ajuste do modelo foram analisados. Byrne (2016) adverte que a razão entre o qui-quadrado e os graus de liberdade não deve exceder 5 (CMIN/DF). O Comparative Fit Index (CFI) varia de zero a um, sendo valores próximos de um são indicativos de bom ajuste. O índice parcimonioso Root Mean Square Error of Approximation (RMSEA) indica um modelo de ajuste adequado quando seu valor é menor que 0,1 . $\mathrm{O}$ índice de parcimônia Parsimony Comparative Fit Index (PCFI) deve ser maior que 0,60. O índice absoluto Stardardized Root Mean Square Residual é a diferença entre a correlação normalizada observada e a correlação previsível e deve ser menor que 0,1 (Marôco, 2010). Os índices de ajuste do modelo confirmatório foram todos adequados (CMIN/DF=2,30; $\mathrm{CFI}=0,93 ; \mathrm{PCFI}=0,77$; RMSEA=0,07; E SRMR=0,04). 
A última etapa consistiu na verificação da validade convergente e discriminante dos itens e dimensões do modelo. Em relação à primeira, observa-se que a maioria dos itens apresentou uma estimativa padronizada superior à 0,50 , com exceção do item Saud2 ("Eu não me considero um consumidor com consciência saudável"), com estimativa de 0,220. Além disso, o rho de Jöreskog de todas as dimensões foi calculado e a maioria foi superior à 0,70 . Foram eles: 0,58 (Consciência Saudável), 0,96 (Atitude), 0,94 (Norma Subjetiva Social), 0,95 (Norma Subjetiva Interna), 0,72 (Controle Percebido), 0,91 (Confiança no Sistema), 0,67 (Confiança Pessoal), 0,94 (Intenção de Compra). Quanto à variância extraída do construto Consciência Saudável, o valor encontrado foi de 0,48, um pouco abaixo, mas próximo ao recomendado por Hair et al.(2005). Os demais valores ficaram acima de 0,5, como mostrado na Tabela 1. Diante de todos esses indicadores, a validade convergente foi confirmada.

Para avaliar a validade discriminante, a variância extraída (AVE) deve ser maior do que as correlações entre as dimensões elevadas ao quadrado, conforme Hair, Gabriel e Patel (2014). A Tabela 1 mostra que a validade discriminante do modelo foi comprovada.

Tabela 1: Validade discriminante dos construtos

\begin{tabular}{|l|l|l|l|l|l|l|l|l|}
\hline & $\begin{array}{l}\text { Cons. } \\
\text { Saud. }\end{array}$ & Atitude & $\begin{array}{l}\text { Norma } \\
\text { Sub. S. }\end{array}$ & $\begin{array}{l}\text { Norma } \\
\text { Sub.I. }\end{array}$ & Controle & Conf.Sist. & Conf.Pes. & Intenção \\
\hline $\begin{array}{l}\text { Cons. } \\
\text { Saud. }\end{array}$ & $\mathbf{0 , 4 8}^{\mathbf{a}}$ & & & & & & & \\
\hline Atitude & 0,20 & $\mathbf{0 , 9 1}^{\text {a }}$ & & & & & & \\
\hline $\begin{array}{l}\text { Norma } \\
\text { Sub. S. }\end{array}$ & 0,21 & 0,36 & $\mathbf{0 , 8 6}{ }^{\text {a }}$ & & & & & \\
\hline $\begin{array}{l}\text { Norma } \\
\text { Sub. I. }\end{array}$ & 0,16 & 016 & $\mathbf{0 , 3 2}$ & $\mathbf{0 , 9 0}^{\text {a }}$ & & & & \\
\hline Controle & 0,37 & 0,11 & 0,15 & $\mathbf{0 , 1 5}$ & $\mathbf{0 , 5 4}^{\text {a }}$ & & & \\
\hline Conf.Sist. & 0,06 & 0,01 & 0,02 & 0,03 & 0,16 & $\mathbf{0 , 7 8}^{\text {a }}$ & & \\
\hline Conf.Pes. & 0,00 & 0,00 & 0,00 & 0,00 & 0,05 & 0,00 & $\mathbf{0 , 6 2}^{\text {a }}$ & \\
\hline Intenção & 0,30 & 0,37 & 0,49 & 0,31 & 0,25 & 0,01 & 0,00 & $\mathbf{0 , 9 1}^{\text {a }}$ \\
\hline
\end{tabular}

Nota. ${ }^{a}$ Variância extraída. Números fora da diagonal são os valores das correlações entre as variáveis latentes elevadas ao quadrado.

Após a confirmação do modelo de mensuração, a Modelagem por Equações Estruturais foi realizada a fim de verificar as relações propostas no modelo de pesquisa. Para isso, três modelos foram testados e analisados. O primeiro deles, o Modelo 1, refere-se ao modelo teórico de pesquisa apresentado na Figura 1, ou seja, testou-se a influência das Normas Subjetivas (Social e Interna), do Controle Percebido, da Atitude, da Consciência Saudável, da Confiança no Sistema e da Confiança Pessoal na intenção de compra.

Os resultados das relações de predição do Modelo 1 são apresentados na Tabela 2 e na Figura 3.

Tabela 2: Estimativas do modelo teórico de pesquisa (Modelo 1)

\begin{tabular}{lcccc} 
& Estimativa & Erro padron. & C.R. & $\begin{array}{c}\text { Estimativa da } \\
\text { regressão padron. }\end{array}$ \\
\hline Norma Sub. S. $\rightarrow$ Intenção & 0,43 & 0,08 & 5,43 & $0,36^{* *}$ \\
Norma Sub. I. $\rightarrow$ Intenção & 0,17 & 0,06 & 2,63 & $0,15^{* *}$ \\
Atitude $\rightarrow$ Intenção & 0,30 & 0,08 & 3,66 & $0,22^{* *}$ \\
Controle $\rightarrow$ Intenção & 0,25 & 0,09 & 2,74 & $0,18^{* *}$ \\
Cons. saudável $\rightarrow$ Intenção & 0,16 & 0,08 & 1,96 & $0,13^{*}$ \\
Confiança Sist. $\rightarrow$ Intenção & $-0,09$ & 0,057 & $-1,56$ & $-0,08$ \\
Confiança Pess. $\rightarrow$ Intenção & $-0,07$ & 0,07 & $-1,10$ & $-0,05$ \\
\hline Nota. $*$ p $<0,05 ; *$ * $<0,01$ & & & &
\end{tabular}


Os resultados do Modelo 1 mostraram que a consciência saudável, atitude, controle percebido e normas subjetivas influenciam de forma significativa a intenção de compra. Por outro lado, a confiança no Sistema (p-valor $=0,11)$ e a Confiança Pessoal (p-valor=0,33) não impactam a intenção de compra. Ou seja, a confirmação de H1 e H3 e a não confirmação de H2.

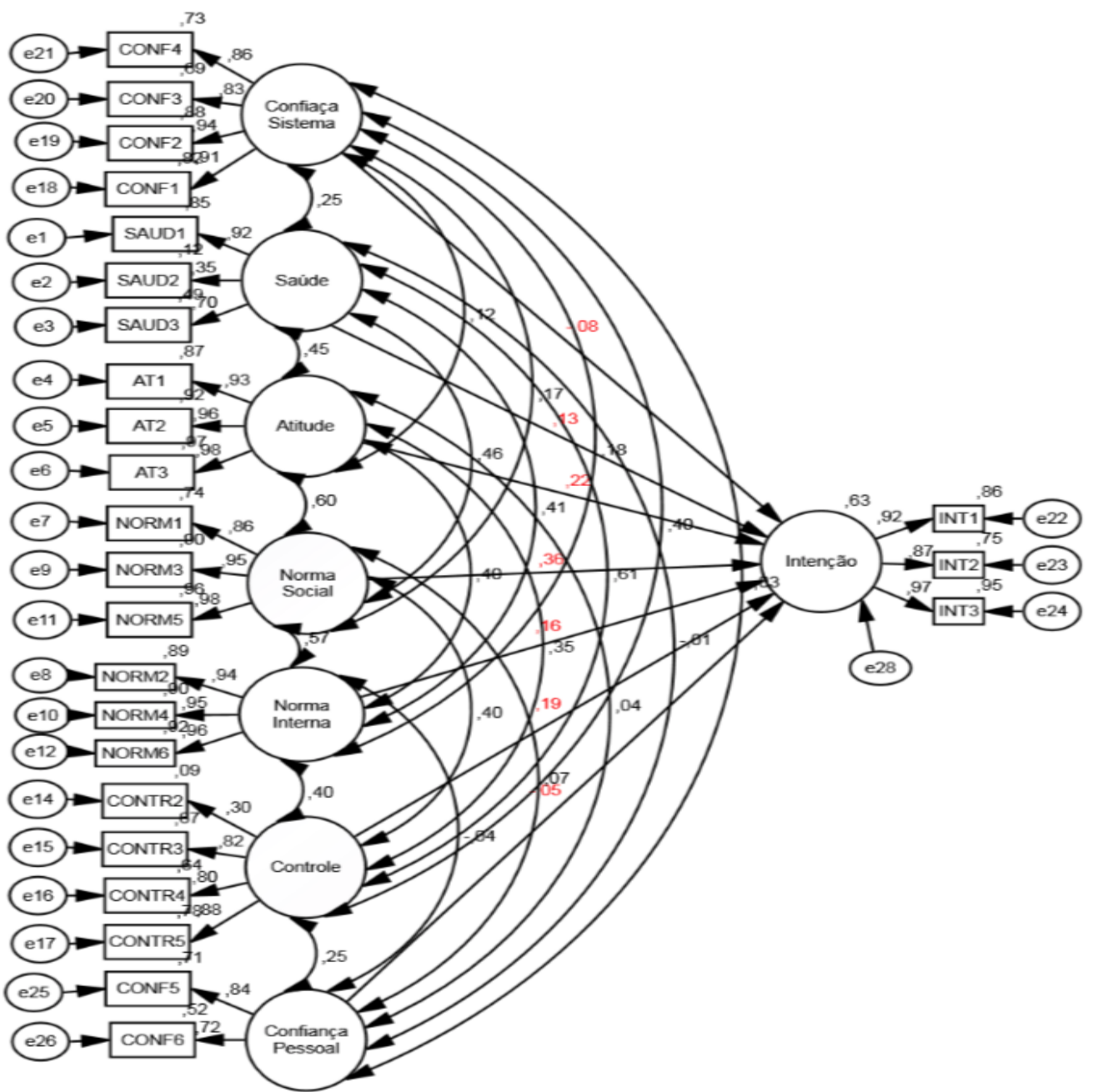

Figura 3. Modelo estrutural (Modelo 1) Fonte: Os autores

No Modelo 2 testou-se somente a inserção da Saúde no modelo da TCP. Os resultados foram significativos e são apresentados na Tabela 3 e na Figura 4.

Tabela 3: Estimativas do modelo da TCP com inclusão de saúde (Modelo 2)

\begin{tabular}{lcccc}
\hline & Estimativa & Erro padron. & C.R & $\begin{array}{c}\text { Estimativa da regressão } \\
\text { padron. }\end{array}$ \\
\hline Normas Sub. S. $\rightarrow$ Intenção & 0,42 & 0,08 & 5,31 & $0,35^{* *}$ \\
Normas Sub. I. $\rightarrow$ Intenção & 0,18 & 0,06 & 2,79 & $0,16^{* *}$ \\
Atitude $\rightarrow$ Intenção & 0,30 & 0,08 & 3,70 & $0,22^{* *}$ \\
Controle $\rightarrow$ Intenção & 0,15 & 0,07 & 1,98 & $0,13^{*}$ \\
Cons. Saudável $\rightarrow$ Intenção & 0,17 & 0,08 & 2,04 & $0,15^{*}$ \\
\hline
\end{tabular}

\footnotetext{
Nota. ${ }^{*} \mathrm{p}<0,05 ; * * \mathrm{p}<0,01$.
} 
A dimensão de Norma Subjetiva Social $(\beta=0,35)$ foi a principal preditora da intenção de compra, seguida da atitude $(\beta=0,22)$, da Norma Subjetiva Interna $(\beta=0,16)$, da Consciência Saudável $(\beta=0,15)$ e do Controle percebido $(\beta=0,13)$, totalizando um $\mathrm{R}^{2}$ de $62 \%$.

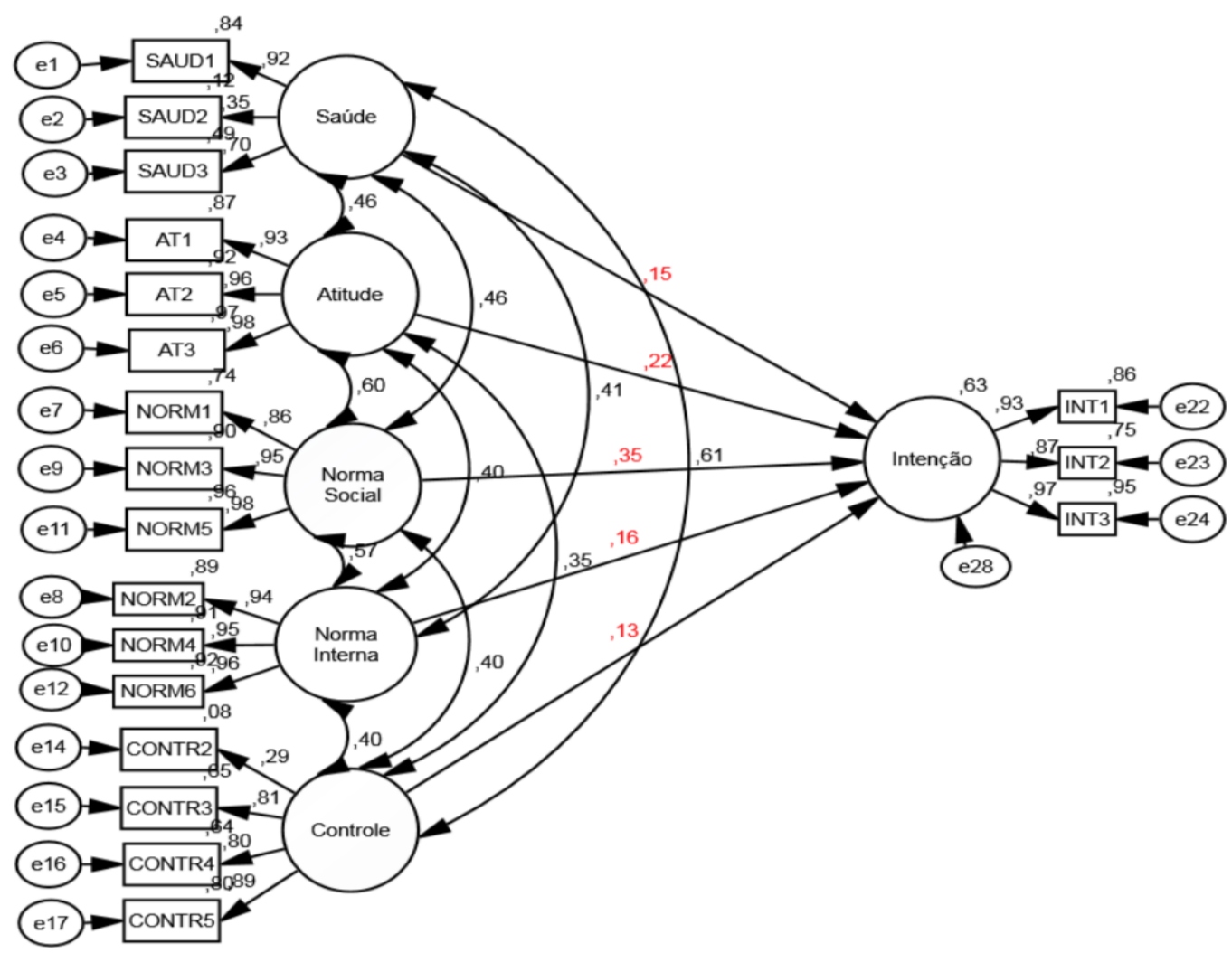

Figura 4. Modelo estrutural (Modelo 2)

Fonte: Os autores

Para finalizar, no Modelo 3, a TCP foi avaliada em sua estrutura original (apenas H1), sem a inserção de nenhuma nova dimensão. Os resultados são mostrados na Tabela 4 e na Figura 5.

Tabela 4: Estimativas do modelo original da TCP (Modelo 3)

\begin{tabular}{lcccc}
\hline & Estimativa & Erro padron. & C.R. & $\begin{array}{c}\text { Estimativa da regressão } \\
\text { padron. }\end{array}$ \\
\hline Norma Sub. S. $\rightarrow$ Intenção & 0,44 & 0,08 & 5,49 & $0,37^{* *}$ \\
Normas Sub. I. $\rightarrow$ Intenção & 0,19 & 0,06 & 2,97 & $0,18^{* *}$ \\
Atitude $\rightarrow$ Intenção & 0,34 & 0,08 & 4,23 & $0,25^{* *}$ \\
Controle $\rightarrow$ Intenção & 0,22 & 0,06 & 3,54 & $0,20^{* *}$ \\
\hline
\end{tabular}

Nota. ${ }^{*} \mathrm{p}<0,05 ; * * \mathrm{p}<0,01$.

Assim como no Modelo 2, a Norma Subjetiva Social $(\beta=0,37)$ foi a maior preditora da intenção de compra, seguida da Atitude $(\beta=0,25)$, do Controle Percebido $(\beta=0,20)$ e da Norma Subjetiva Interna $(\beta=0,18)$. Nota-se que, com a retirada da dimensão Consciência Saudável, o Controle Percebido ganha mais força com o aumento de sua estimativa (ß). $O \mathrm{R}^{2}$ foi de $61 \%$. $\mathrm{O}$ modelo estrutural é detalhado na Figura 5. 


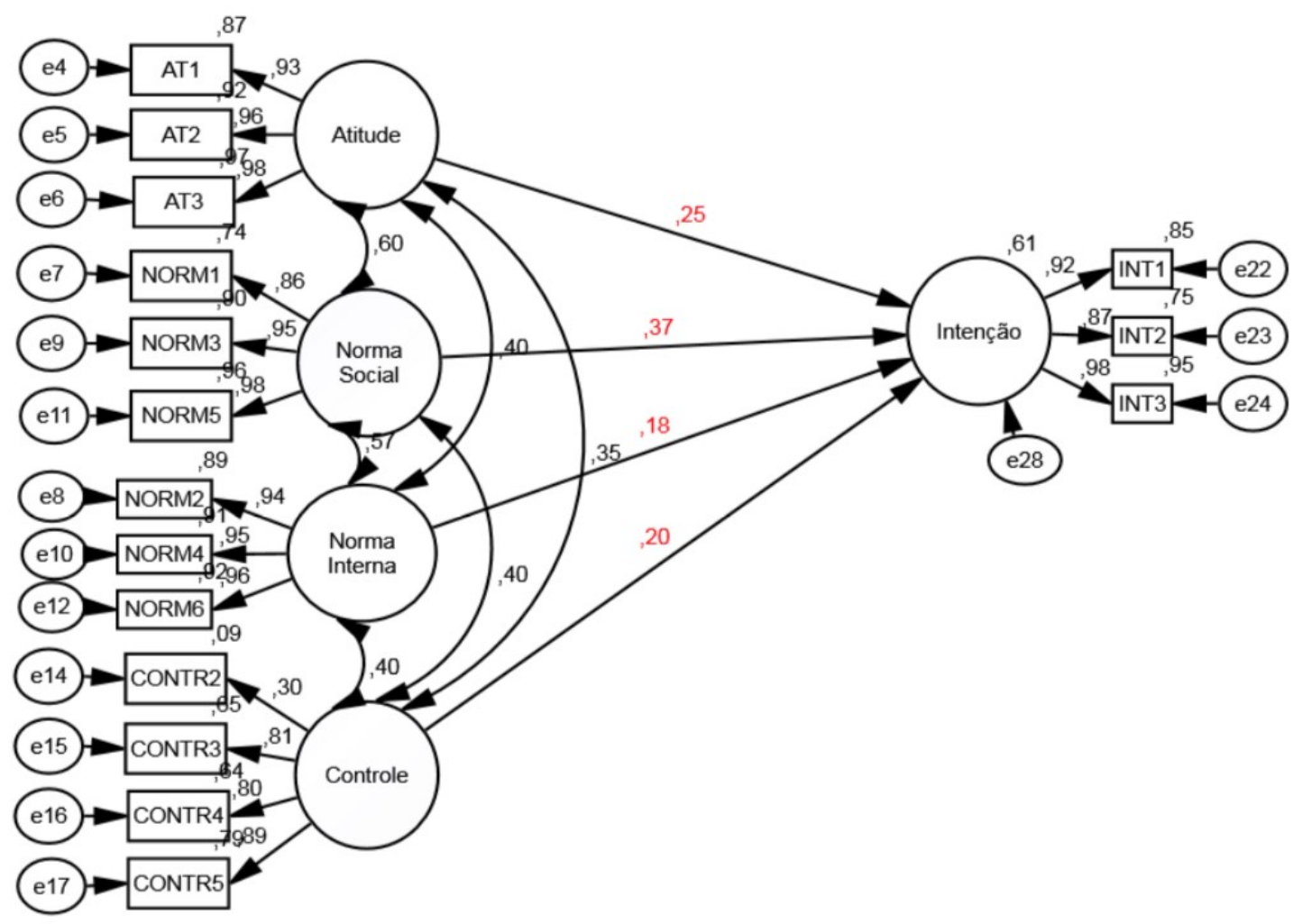

Figura 5. Modelo estrutural (Modelos 3)

Fonte: Os autores

A Tabela 5 apresenta os índices de ajuste dos Modelos 2 e 3 bem como o $\mathrm{R}^{2}$ associado à intenção de compra. O Modelo 1 foi descartado, já que a confiança não foi significativa para explicar a intenção de compra (não confirmação de H2).

Tabela 5: Comparação entre os Modelos 2 e 3

\begin{tabular}{lcccccc}
\hline & $\mathrm{R}^{2}$ Intenção de compra & CMIN/DF & CFI & SRMR & RMSEA & PCFI \\
\hline Modelo 2 & 0,62 & 2,78 & 0,94 & 0,05 & 0,09 & 0,75 \\
Modelo 3 & 0,61 & 3,34 & 0,94 & 0,03 & 0,10 & 0,73 \\
\hline
\end{tabular}

A comparação apresentada na Tabela 5 mostra que o Modelo 2 apresenta o melhor ajuste e o maior $\mathrm{R}^{2}$. Porém, a diferença dos indicadores do Modelo 2 e do Modelo 3 foi pequena. Isso mostra que a Consciência Saudável influencia a intenção de compra (confirmação de H3), mas com uma predição pequena $(\beta=0,15)$. Os resultados encontrados serão discutidos no próximo tópico.

\section{DISCUSSÃO}

De acordo com os resultados da pesquisa, especificamente no enfoque da TCP nos Modelos 2 e 3, a dimensão Norma Subjetiva Social é a que mais influencia a intenção de compra dos tipos alimentos orgânicos investigados, seguida pela Atitude, Controle Comportamental Percebido e Norma Subjetiva Interna. A Consciência Saudável, testada no Modelo 2, impacta positivamente a intenção de compra, porém, com uma predição baixa. Por fim, as análises ainda mostraram que a confiança não influencia diretamente a intenção de compra (Modelo 1). Ou seja, houve a confirmação das hipóteses $\mathrm{H} 1$ e H3 e a não confirmação de H2. Nesta seção, os resultados serão discutidos à luz da literatura com a apresentação de estudos que fundamentaram essa pesquisa.

No estudo de Hoppe et al. (2013), realizado em Porto Alegre, a TCP, foi empregada com os consumidores de tomates orgânicos de dois canais de distribuição (supermercado e feira ecológica). Os resultados mostraram que a atitude e controle percebido influenciam positivamente a intenção de compra. Porém, na pesquisa de Hoppe et al. (2013), as normas subjetivas não foram significativas 
para o modelo e ele foi validado parcialmente. Os autores atribuíram esse resultado pela utilização de um único item para medir as Normas Subjetivas, o que realmente pode ter limitado os resultados da modelagem por equações estruturais do estudo em Porto Alegre. Todavia, este estudo permitiu a validação completa da TCP para alimentos orgânicos (Modelo 3) e, ainda, identificou a grande importância da norma subjetiva social na intenção de compra destes alimentos.

Outro estudo que testou a influência das dimensões da TCP sobre a intenção de compra orgânica foi o de Dean et al. (2012), realizado no Reino Unido. Nele, a atitude e a norma subjetiva apresentaram um bom desempenho como preditores da intenção de compra de tomates orgânicos frescos versus tomates processados. Esta pesquisa apontou essas duas dimensões como as que mais influenciam a intenção de compra de alimentos orgânicos, confirmando os resultados encontrados pelos autores. São resultados que corroboram os obtidos por Nuttavuthisit e Thøgersen (2017), que identificaram que a atitude e a norma subjetiva influenciam a intenção de compra de alimentos orgânicos na Tailândia. No que se refere ao controle comportamental percebido, o item relativo a preços altos não foi significativo na Tailândia, assim como aconteceu no Brasil.

Este estudo também corrobora com o de Qi e Angelika (2019) e o de Shin, Im, Jung e Severt (2018). O primeiro apontou a importância das dimensões da TCP na explicação da intenção de compra de alimentos saudáveis na China. Nele, as normas subjetivas se destacaram. Enquanto isso, o estudo de Shin et al. (2018) teve como foco a escolha de menu orgânico de restaurantes dos Estados Unidos e também mostrou a importância das normas subjetivas, do controle comportamental e da atitude na previsão da intenção de compra dos consumidores.

O estudo de Yazdanpanah e Forouzani (2015) constatou uma relação significativa entre atitude e intenção de compra orgânica no Irã. Entretanto, as dimensões das normas subjetivas e do controle comportamental percebido não se mostraram preditores significativos de intenção, divergindo dos resultados aqui encontrados. Segundo Yazdanpanah e Forouzani (2015), o preditor atitude é mais forte do que as outras variáveis, pois o comportamento de consumir alimentos orgânicos é muito individual e, consequentemente, influenciado por uma variedade de crenças individuais no Irã. Nessa pesquisa, no entanto, a norma subjetiva social e a atitude se mostraram as mais fortes. Portanto, o contexto cultural em que as pesquisas foram aplicadas pode ter causado a divergência de resultados, principalmente, considerando que normas subjetivas têm uma relação direta com aspectos culturais (Ajzen, 1991).

O estudo de Liang (2014) buscou integrar estilo de vida à TCP. Nele as três dimensões da TCP motivaram a intenção de compra online de orgânicos. Este resultado é compatível com os encontrados nesse estudo. Todavia, Liang identificou a atitude com maior influência sobre a intenção de compra e a norma subjetiva foi o construto que menos influenciou a intenção. Essa diferença parcial de resultados pode ter ocorrido pelo fato de a pesquisa de Liang (2014) ter sido restrita ao comportamento de compra online de orgânicos.

No estudo de Yadav e Pathak (2016), a consciência saudável teve um maior poder preditivo no modelo. A adição dos preditores atitude moral, consciência saudável e preocupação com o meio ambiente melhorou o ajuste do modelo e o $\mathrm{R}^{2}$ de explicação da intenção de compra orgânica aumentou. A TCP apoiou parcialmente a intenção de compra, pois, diferentemente da presente pesquisa, a norma subjetiva não apresentou influência significativa. Como esse estudo foi desenvolvido na Índia, sugere-se que, assim como no comparativo com o estudo do Irã (Yazdanpanah \& Forouzani, 2015), a diferença de contextos culturais possa ter contribuído para que os resultados fossem divergentes. Adicionalmente, os estudos de Lima-Filho e Quevedo-Silva (2012) e de Andrade e Bertoldi (2012) também confirmaram a importância de aspectos relacionados à saúde na percepção do consumidor a respeito dos alimentos orgânicos, contribuindo para os resultados encontrados nessa pesquisa.

Apesar de a Consciência Saudável influenciar a intenção de compra, sua predição foi baixa. Uma possível explicação para isso seria o anseio do consumidor em buscar na alimentação benefícios a curto prazo. Assim, como o consumo de algumas substâncias usadas no sistema agroalimentar convencional gera consequências nocivas à saúde no logo prazo (Sousa, Azevedo, 
Lima, \& Silva, 2012), é possível que os benefícios da ingestão de alimentos orgânicos só sejam percebidos pelo consumidor também no longo prazo, contribuindo para o impacto pouco significativo da dimensão Consciência Saudável neste estudo.

Outra possível explicação para a baixa predição da dimensão consciência saudável seria a falta de informação dos consumidores a respeito de alimentos orgânicos. Apesar de a dimensão Controle Comportamental Percebido ser significativa no Modelo 2 e incluir a percepção do consumidor em relação ao seu conhecimento, a compreensão do mesmo acerca do assunto não foi efetivamente medida nesse estudo. Talvez as informações que o consumidor detém estejam restritas a uma associação simplista de que alimentos orgânicos envolvem apenas a isenção de agrotóxicos, deixando de lado os demais processos e cuidados que os compreendem e as suas consequências para a saúde. Diante disso, a expectativa social percebida pelo indivíduo em relação à sua compra de alimentos orgânicos, representada pela dimensão norma subjetiva social, acaba ganhando força sobre a intenção de compra orgânica, como visto nos resultados aqui encontrados. Ou seja, é possível que o indivíduo tenha a intenção de comprar FLH orgânicas não porque tem o discernimento sobre o sistema orgânico de produção e seus benefícios, mas sim pela existência de uma forte influência social do seu círculo ou grupos de referência para executar tal comportamento.

Como já ressaltado, ao contrário do esperado, a confiança não foi preditora da intenção de compra (Modelo 1). Esse resultado refuta alguns estudos, entre eles o de Teng e Wang (2015) e o de Won Suh et al. (2015), que constaram a influência positiva da confiança na intenção de compra dos consumidores. Já o estudo de Andrade e Bertoldi (2012) verificou que os consumidores de Belo Horizonte não se certificam se o alimento realmente é orgânico pela presença do selo, fato ligado diretamente à confiança. Além disso, cerca de metade dos entrevistados não soube dizer se o selo de certificação estava presente nos alimentos orgânicos que eles consumiam, o que pode indicar a falta de informação do consumidor acerca da certificação. Isso pode explicar parcialmente os resultados aqui encontrados.

Adicionalmente, Hoogland, Boer e Boersema (2007) fizeram um experimento junto aos consumidores de um supermercado da Holanda, com o objetivo de compreender a influência de diferentes rótulos na escolha de alimentos sustentáveis. Testou-se o impacto do certificado de orgânico com e sem o painel de informações que trazia dados adicionais sobre o certificado. Os resultados revelaram que os consumidores não compreendem completamente a certificação orgânica. Quando essa certificação é aliada ao painel de informações, a crença dos consumidores sobre os produtos acaba aumentando. Apesar disso, o impacto sobre a intenção de compra foi pequeno nas duas modalidades de certificação. Assim como o consumidor holandês, há indícios de que o consumidor brasileiro não tem uma boa compreensão sobre a certificação orgânica e os processos que a envolvem. Portanto, o estudo holandês, mesmo não mensurando o efeito da confiança sobre a intenção de compra, pode contribuir para a explicação da não confirmação de $\mathrm{H} 2$ nessa pesquisa.

\section{CONSIDERAÇÕES FINAIS}

Esta pesquisa teve como objetivo analisar os fatores que influenciam a intenção de compra e de alimentos orgânicos com o acréscimo da confiança do consumidor e da consciência saudável no modelo da Teoria do Comportamento Planejado. Os resultados mostraram que as Normas Subjetivas, Atitude e Controle percebido influenciam diretamente a intenção de compra. Em contrapartida, a Confiança não foi significativa no modelo de predição. Por fim, a Consciência Saudável impactou a intenção de compra, mas de forma pouco expressiva, sendo quase irrelevante o seu acréscimo ao modelo.

Esta pesquisa possui diversas contribuições. A primeira contribuição refere-se ao aprofundamento do estudo sobre os principais fatores que influenciam o consumo de alimentos orgânicos. Esse assunto ainda é incipiente no Brasil, principalmente, se o foco for pesquisas sobre alimentos orgânicos que utilizam a Teoria do Comportamento Planejado como base. Entretanto, em 
âmbito internacional, o assunto é mais difundido e os preditores mais estudados fazem parte dessa teoria. Portanto, esta pesquisa contribuiu para a diminuição da lacuna sobre esse tema na produção brasileira e na avaliação do mercado brasileiro de alimentos orgânicos.

Como contribuição teórica, verificou a inserção de duas dimensões no modelo da TCP. Além de contemplar os preditores mais estudados internacionalmente (atitude, norma subjetiva e controle comportamental percebido), o modelo incluiu, de acordo com a literatura, o principal preditor nacional (consciência saudável), bem como a dimensão confiança, apontada como relevante neste mercado. Ademais, deixa clara a importância de se avaliar as normas subjetivas em dois níveis, social e individual, ao invés de maneira agrupada, a fim de se obter um melhor entendimento de cada mercado analisado. Dessa forma, a escala que mede as dimensões da TCP adaptada por Nuttavuthisit e Thøgersen (2017) apresentou evidências de validação no contexto brasileiro e pode ser utilizada em futuros estudos.

Com relação às contribuições gerenciais, esse estudo identificou os fatores que motivam a compra de FLH orgânicas. Os resultados revelaram a importância da norma subjetiva social e da atitude para explicar a intenção de compra de alimentos orgânicos. O indivíduo possui a intenção de comprar FLH orgânicas, pois avalia esse comportamento como positivo e crê na existência de uma pressão social para executá-lo. Isso significa que os gestores inseridos no mercado de orgânicos podem investir e desenvolver estratégias para aumentar o valor percebido pelo cliente em relação ao consumo desses produtos. Os dados também chamam a atenção dos gestores sobre a importância do marketing de referência (ou boca a boca). As opiniões das referências sociais importantes para o indivíduo têm grande potencial de influência sobre a intenção de compra de alimentos orgânicos.

Com relação ao controle comportamental percebido, nota-se que a disponibilidade e o conhecimento dos consumidores a respeito de alimentos orgânicos influenciam sua intenção de compra. Diante disso, é preciso se atentar para a logística de maneira que as FLH orgânicas estejam disponíveis para o consumidor no local e tempo convenientes. Os resultados também possibilitam que os gestores planejem meios para aumentar o conhecimento das pessoas quanto aos diferenciais dos alimentos orgânicos.

Apesar do zelo e rigor metodológico em sua elaboração, esta pesquisa possui limitações. Os resultados não podem ser generalizados, já que se utilizou da amostragem não-probabilística por conveniência. Além disso, a pesquisa não abordou diversos tipos de alimentos orgânicos, somente as FLH.

Com relação à agenda de pesquisa, sugere-se que as relações estudadas sejam aplicadas em outros contextos culturais. Testar e confrontar o modelo em diferentes locais do Brasil também pode ser feito. Outra sugestão seria expandir os tipos de alimentos orgânicos pesquisados, pois o resultado poderia variar de acordo com o produto, se in natura, se processado. Recomenda-se, ainda, utilizar o modelo da TCP para comparar os fatores que influenciam a intenção de compra entre alimentos orgânicos e convencionais. Quanto à escala de controle comportamental percebido, propõe-se que sejam incluídos mais itens ligados ao preço de alimentos orgânicos. Por fim, apesar de a questão da saúde ter sido pouco relevante, é importante que estudos posteriores verifiquem esta variável com outras medidas e amostras mais abrangentes.

\section{REFERÊNCIAS}

Ajzen, I. (1985). From intentions to actions: a theory of planned behavior. In J. Kuhl \& J. Beckmann (Eds.), Action control: from cognition to behavior, 11-39. Berlin, Heidelberg: Springer Berlin Heidelberg.

Ajzen, I. (1991). The theory of planned behavior. Organizational Behavior and Human Decision Processes, 50(2), 179-211.

Ajzen, I. (2002). Perceived behavioral control, self-efficacy, locus of control, and the theory of planned behavior1. Journal of Applied Social Psychology, 32, 665-683. 
Ajzen, I., \& Fishbein, M. (1980). Understanding attitudes and predicting social behavior. New Jersey: Prentice-Hall.

Albuquerque Júnior, E. P., Silva Filho, J. C. L., Costa, J. S., \& Santos, S. M. (2013). Aspectos relativos à saúde e ao meio ambiente ligados ao consumo de alimentos orgânicos. Revista de Administração da Ufsm, 6, 295-312.

Andrade, L. M. S., \& Bertoldi, M. C. (2012). Atitudes e motivações em relação ao consumo de alimentos orgânicos em Belo Horizonte, MG. Brazilian Journal of Food Technology, 15(spe.), 3140 .

Armstrong, J., Morwitz, V., \& Kumar, V. (2000). Sales forecasts for existing consumer products and services: do purchase intentions contribute to accuracy?" International Journal of Forecasting, $16,383-397$.

Braga Junior, S. S., Veiga Neto, A. R., \& Moraes, N. R. (2014). Atributos de estilo de vida do consumidor relacionados ao consumo de produtos orgânicos no varejo especializado. Revista Brasileira de Marketing, 13(5), 36-46.

Brislin, R. W. (1970). Back-Translation for cross-cultural research. Journal of Cross-Cultural Psychology, 1(3), 185-216.

Brown, T. A. (2014). Confirmatory factor analysis for applied research. New York: Guilford Publications.

Byrne, B. M. (2016). Structural equation modeling with Amos: basic concepts, applications, and programming. New York: Routledge.

Cohen, J. (1992). A power primer. Psychological Bulletin, 112(1), 155-159.

Dean, M., Raats, M. M., \& Shepherd, R. (2012). The role of self-identity, past behavior, and their interaction in predicting intention to purchase fresh and processed organic Food. Journal of Applied Social Psychology, 42(3), 669-688.

Gallo, M. P., Llorens Marín, M., \& Talledo Flores, H. (2014). El factor de la percepción de control como determinante en la intención de compra de productos ecológicos. Innovar, 24(54), 139-152.

Giannakas, K. (2002). Information asymmetries and consumption decisions in organic food product markets. Canadian Journal of Agricultural Economics/Revue Canadienne D\&apos;agroeconomie, $50(1), 35-50$.

Hair, J. F., Anderson, R. E., Tatham, R. L., \& Black, W. C. (2005). Análise multivariada de dados. Porto Alegre: Bookman Editora.

Hair, J.F., Gabriel, M.L.D.S., \& Patel, V.K. (2014). Modelagem de equações estruturais baseada em covariância (CB-SEM) com o Amos: orientações sobre sua aplicação como uma ferramenta de pesquisa de markerting. ReMark, 12 (2), 44-55. .

Hoogland, C. T., de Boer, J., \& Boersema, J. J. (2007). Food and sustainability: do consumers recognize, understand and value on-package information on production standards? Appetite, 49(1), 47-57.

Hoppe, A., Vieira, L. M., \& de Barcellos, M. D. (2013). Consumer behaviour towards organic food in porto alegre: an application of the theory of planned behaviour. Revista de Economia e Sociologia Rural, 51(1), 69-90. Retrieved from internal-pdf://144.156.249.43/Hoppe-2013Consumer

Janssen, M., \& Hamm, U. (2014). Governmental and private certification labels for organic food: consumer attitudes and preferences in germany. Food Policy, 49, 437-448. Retrieved from https://doi.org/https://doi.org/10.1016/j.foodpol.2014.05.011 
Kuo, Y.-F., Wu, C.-M., \& Deng, W.-J. (2009). The relationships among service quality, perceived value, customer satisfaction, and post-purchase intention in mobile value-added services.

Computers in Human Behavior, 25(4), 887-896.

Liang, A. R.-D. (2014). Enthusiastically consuming organic food: an analysis of the online organic food purchasing behaviors of consumers with different food-related lifestyles. Internet Research, 24(5), 587-607.

Lima-Filho, D. de O., \& Quevedo-Silva, F. (2012). Percepção do consumidor sobre produtos orgânicos. REMark, 11(1), 29-46.

Lombardi, M. S., Moori, R. G., \& Sato, G. S. (2004). Um estudo exploratório dos fatores relevantes na decisão de compra de produtos orgânicos. Revista de Administração Mackenzie, 5(1), 13-34.

Marôco, J. (2010). Análise de equações estruturais: fundamentos teóricos, software \& aplicações. Pêro Pinheiro: ReportNumber.

Nuttavuthisit, K., \& Thøgersen, J. (2017). The importance of consumer trust for the emergence of a market for green products: the case of organic food. Journal of Business Ethics, 140(2), 323-337.

Conselho Brasileiro da Produção Orgânica e Sustentável - Organis / Market Analysis (2017).

Consumo de produtos orgânicos no Brasil: primeira pesquisa nacional sobre o consumo de orgânicos. Recuperado de https://organis.org.br/wp-content/uploads/2018/11/Pesquisa-Consumode-Produtos-Orgânicos-no-Brasil.pdf.

Pasquali, L. (1999). Instrumentos psicológicos: manual prático de elaboração. Brasília: LabPAM/Ibapp, 306.

Qi, X., \& Ploeger Angelika, A. (2019). Explaining consumers' intentions towards purchasing green food in Qingdao, China: the amendment and extension of the theory of planned behavior. Appetite, $133(1), 414-422$.

Rife, S. C., Cate, K. L., Kosinski, M., \& Stillwell, D. (2016). Participant recruitment and data collection through Facebook: the role of personality factors. International Journal of Social Research Methodology, 19(1), 69-83.

Rodrigues, R. R., Carlos, C. C., Mendonça, P. S. M., \& Correa, S. R. A. (2009). Atitudes e fatores que influenciam o consumo de produtos orgânicos no varejo. Revista Brasileira de Marketing, $8(1)$, $164-186$.

Rousseau, D., Sitkin, S., Burt, R., \& Camerer, C. (1998). Not so different after all: a cross-discipline view of trust. Academy of Management Review, 23.

Scalco, A., Noventa, S., Sartori, R., \& Ceschi, A. (2017). Predicting organic food consumption: a meta-analytic structural equation model based on the theory of planned behavior. Appetite, 112, $235-248$.

Shin, Y. H., Im, J., Jung, S. E., \& Severt, K. (2018). The theory of planned behavior and the norm activation model approach to consumer behavior regarding organic menus. International Journal of Hospitality Management, 69, 21-29.

Sousa, A. A. de, Azevedo, E. de, Lima, E. E. de, \& Silva, A. P. F. da. (2012). Alimentos orgânicos e saúde humana: estudo sobre as controvérsias, 31(8), 513-517.

Tarkiainen, A., \& Sundqvist, S. (2005). Subjective norms, attitudes and intentions of finnish consumers in buying organic food. British Food Journal, 107, 808-822.

Teng, C.-C., \& Wang, Y.-M. (2015). Decisional factors driving organic food consumption. British Food Journal, 117(3), 1066-1081. Retrieved from https://search.proquest.com/docview/1654658886?accountid=26646 
Torjusen, H., Sangstad, L., Jensen, K. O., \& Kjærnes, U. (2004). European consumers' conceptions of organic food: a review of available research. Oslo: National Institute for Consumer Research.

Vassallo, M., Scalvedi, M. L., \& Saba, A. (2016). Investigating psychosocial determinants in influencing sustainable food consumption in Italy. International Journal of Consumer Studies, 40(4), 422-434.

Webb, T. L., \& Sheeran, P. (2006). Does changing behavioral intentions engender behavior change? A meta-analysis of the experimental evidence. Psychological Bulletin, 132(2), 249-268.

Willer, H., \& Lernoud, J. (2018). The world of organic agriculture. Statistics and emerging trends 2018. Bonn, Germany: Research Institute of Organic Agriculture (FiBL), Frick, and Ifoam Organics International.

Won Suh, B., Eves, A., \& Lumbers, M. (2015). Developing a model of organic food choice behavior. Social Behavior and Personality: an International Journal, 43.

Wu, P. C. S., Yeh, G. Y.-Y., \& Hsiao, C.-R. (2011). The effect of store image and service quality on brand image and purchase intention for private label brands. Australasian Marketing Journal (AMJ), 19(1), 30-39.

Yadav, R., \& Pathak, G. S. (2016). Intention to purchase organic food among young consumers: evidences from a developing nation. Appetite, 96, 122-128.

Yazdanpanah, M., \& Forouzani, M. (2015). Application of the theory of planned behaviour to predict iranian students' intention to purchase organic food. Journal of Cleaner Production, 107, $342-352$.

Żakowska-Biemans, S. (2011). Polish consumer food choices and beliefs about organic food. British Food Journal, 113(1), 122-137.

Data da submissão: 01/06/2018

Data de aceite: $17 / 10 / 2018$

Revista de Gestão Social e Ambiental - RGSA, São Paulo, v. 13, n. 1, p. 02-20, jan./abr. 2019. 